\title{
Questões sociocientíficas: origem, características, perspectivas e possibilidades de implementação no ensino de ciências a partir dos anos iniciais do Ensino Fundamental
}

Socio-scientific issues: origin, characteristics, perspectives and possibilities of implementation in science education from the early years of Elementary School

Cinthia Leticia de Carvalho Roversi Genovese ${ }^{1}$ Luiz Gonzaga Roversi Genovese ${ }^{2}$ Washington Luiz Pacheco de Carvalho ${ }^{3}$

\section{Resumo}

Este ensaio tem como objetivo discutir a importância das questões sociocientíficas como uma possibilidade de implementar em sala de aula um ensino de ciências crítico, que contemple as diferentes opiniões dos estudantes e que amplie a compreensão das relações entre ciência e tecnologia, imersas em uma sociedade dominada por interesses econômicos. Para isso, retoma a origem dessa perspectiva de educação no movimento Ciência, Tecnologia e Sociedade (CTS), explica a natureza das questões sociocientíficas e sua presença na mídia, articuladas aos desafios encontrados pelos docentes que decidem trabalhar com temas científicos controversos em suas aulas. Por fim, argumenta que é promissor o estudo de questões sociocientíficas no ensino de ciências a partir dos anos iniciais do Ensino Fundamental.

Palavras-chave: questões sociocientíficas; movimento CTS; formação docente crítica.

\section{Abstract}

This essay aims at discussing the importance of socio-scientific issues as a possibility to implement a critical science teaching in the classroom, that contemplates the different opinions of the students and that broadens the understanding of the relations between science and technology, immersed in a dominated society by economic interests. In order to do so, it retakes the origin of this perspective of education in the Science, Technology and Society (STS) movement, explains the nature of socio-scientific issues and their presence in the media, articulated to the challenges encountered by teachers who decide to work with

\footnotetext{
${ }^{1}$ Universidade Federal de Goiás | cinthiaufg@gmail.com

2 Universidade Federal de Goiás | Igenovese@ufg.br

3 Universidade Estadual Paulista | wlpcarvalho@gmail.com
} 
controversial scientific topics in their classes. Finally, it argues that it is promising the study of socio-scientific issues in science education from the early years of Elementary School.

Keywords: socio-scientific issues; STS movement; critical teacher training.

\section{Introdução}

Este estudo apresenta e discute as potencialidades das questões sociocientíficas ${ }^{4}$ no ensino de ciências, que surgiram a partir do movimento Ciência, Tecnologia e Sociedade (CTS). Esse movimento teve origem no crescente questionamento dos valores e interesses humanos que impulsionam as pesquisas científicas e tecnológicas. É importante perceber que o sistema capitalista investe e direciona grande parte dos avanços na área das ciências.

As guerras, os medicamentos, a indústria da beleza, os meios de transporte, os equipamentos de casa, trabalho e lazer, e todos os demais produtos que estão à venda, não são originados a partir de pesquisas neutras e desinteressadas. Compreender essas relações é fundamental para o ensino de ciências na atualidade. Não basta que os estudantes apenas entendam essa dinâmica relação, mas também sejam capazes de fazer escolhas responsáveis, se posicionando e defendendo seus argumentos. Para isso, também é necessário que o professor aborde em sala de aula a importância de valorizar a vida humana, as diferentes culturas e os demais seres vivos do planeta. A ética e o respeito devem prevalecer em uma educação científica em que os conteúdos estejam articulados aos aspectos sociais e ambientais.

Essa perspectiva da educação em ciências por meio das questões sociocientíficas apresenta desafios como, por exemplo, trabalhar de maneira interdisciplinar, mas também é muito promissora. A mídia traz informações sobre problemas científicos sociais e ambientais que podem ser selecionados e adaptados para serem trabalhados em sala de aula, desde os primeiros anos de escolaridade. Por isso, é essencial uma formação docente crítica, voltada para a valorização da autonomia, para que o professor não tenha receio de explorar junto com seus alunos as questões científicas polêmicas e controversas que podem surgir no cotidiano, e que são importantes na formação para a cidadania.

\section{Surgimento das questões sociocientíficas}

O trabalho com questões sociocientíficas em sala de aula tem suas origens no movimento CTS, que surgiu no século passado para questionar os usos que o ser humano faz da ciência e da tecnologia.

Ao longo da história, é possível perceber que o progresso humano tem o respaldo dos artefatos utilizados em cada época da evolução da nossa espécie (BAZZO, 2014), como por exemplo, as expressões: "Idade da Pedra", separada em "Idade da Pedra Lascada" ou Paleolítico e "Idade da Pedra Polida", ou Neolítico. Há também a "Idade do Bronze", "Idade do Ferro", entre outras.

\footnotetext{
${ }^{4}$ Utilizaremos prioritariamente o termo questões sociocientíficas, no entanto estamos nos referindo à mesma perspectiva de educação quando falamos de temas/assuntos controversos ou temas/assuntos sociocientíficos.
} 
A Revolução Industrial também se tornou um marco do desenvolvimento técnico, trazendo mudanças nas vidas das pessoas. A partir daí todo avanço decorrente do encontro da ciência com a técnica, constituindo o que hoje se conhece como tecnologia, tem sido eficazmente utilizado por grupos dominantes, com o objetivo de impregnar na sociedade contemporânea a ideia que o desenvolvimento humano está linearmente associado ao desenvolvimento científico e tecnológico (BAZZO, 2014).

Algumas pessoas acreditavam que todos os avanços científicos e tecnológicos apenas beneficiavam a humanidade, outras nem sequer conheciam a ciência e algumas pessoas manifestavam revolta contra alguns resultados como, por exemplo, a revolta da vacina, ocorrida no Rio de Janeiro, em 1904. A partir do lançamento das bombas atômicas nas cidades japonesas de Hiroshima e Nagasaki, em 1945, as pessoas que acreditavam apenas nos benefícios científicos passaram a perceber que os avanços na ciência e tecnologia também apresentam seu lado negativo e destrutivo.

As bombas atômicas lançadas no Japão e suas consequências radioativas abriram as portas para uma discussão mais realista, expondo as contradições da suposta neutralidade científica. Essa discussão foi ampliada com a publicação de dois livros, inicialmente nos Estados Unidos, ambos em 1962. O primeiro é o da bióloga marinha, escritora e pesquisadora Rachel Carson, que escreveu a obra "Primavera Silenciosa", onde apresentou dados comprovados de intoxicação animal e humana por resíduos de agrotóxicos no ambiente. Carson (2010) apresentou dados que não eram veiculados na mídia e seu livro, cujo título se refere à contaminação de pássaros, tornou-se rapidamente um best-seller.

O outro livro é do físico teórico Thomas Kuhn, que teve contato com a história da ciência ao se envolver em um curso de física experimental na época em que fazia pós-graduação. Os estudos de Kuhn resultaram na publicação da obra "A Estrutura das Revoluções Científicas", em que o autor compreende que as teorias científicas são discutidas e defendidas em um contexto histórico e social, não sendo, portanto, neutras (KUHN, 2001).

Assim, as pessoas passaram a perceber que o desenvolvimento científico e tecnológico acontece dentro da sociedade e é impulsionado por suas demandas. As atrocidades ocorridas na Guerra do Vietnã também contribuíram para que muitas publicações da época fossem antitecnológicas (BAZZO, 2014).

Nos Estados Unidos, por exemplo, a insatisfação com o ensino de ciências ampliou os esforços para que a Associação Nacional dos Professores de Ciências anunciasse oficialmente, em 1980, a educação CTS como objetivo educacional no país. A partir daí diversos projetos foram financiados por instituições que pesquisavam e implementavam cursos para estudantes, desde a Educação Infantil, até universidades. Cruz (2011) aponta os principais projetos: Ciência através de CTS, Química e comunidade, Programa Chautauqua, Projeto 2061, Projeto Escopo, sequência e coordenação, e Projeto Química do consumidor.

Na Inglaterra, a partir de 1969, as mudanças foram impulsionadas por diversos movimentos dos cidadãos que buscavam transformar a maneira como a ciência estava sendo conduzida (SOLOMON, 1993). As pessoas começaram a criticar principalmente o uso da tecnologia para as guerras, os testes com animais e a degradação ambiental. Elas passaram a exigir maior participação nas decisões que envolvem o financiamento em pesquisas científicas. Para despertar a consciência dos cidadãos e dos futuros cientistas, era preciso realizar uma reforma no ensino de ciências em todos os níveis.

A partir da década de 70, Ziman (1985) percebeu que os cursos enfatizavam os aspectos culturais e sociais da ciência e da tecnologia, e apresentavam diferentes denominações: 
Estudo Social da Ciência, Ciência e Sociedade, Responsabilidade Social na Ciência, Ciência em um Contexto Social e Relações Sociais da Ciência e Tecnologia. Os materiais desses cursos abordavam os aspectos econômicos e sociais dos conceitos científicos. Ziman (1985) percebeu que o movimento era promissor para a educação, mas ainda estava um pouco confuso, por isso, resolveu estudá-lo em profundidade, criando a sigla CTS para o movimento que se apresentava sob diversas denominações.

As discussões continuaram a ocorrer e alguns autores, para dar ênfase ao ambiente preferem utilizar a denominação CTSA (Ciência, Tecnologia, Sociedade e Ambiente), sigla adotada pelo Canadá e Israel, que resultou em importantes mudanças educacionais (AIKENHEAD, 2009). Diversos pesquisadores no Brasil, na Colômbia, em Portugal, entre outros países, também utilizam em suas pesquisas a denominação CTSA (BORTOLETTO; CARVALHO, 2012; GALVÃO; REIS; FREIRE, 2011; MARCONDES et al., 2009; MARTíNEZ, 2012; SASSERON; CARVALHO, 2008).

Mesmo que a dimensão ambiental seja um dos objetivos na educação CTS, a letra A acrescentada à sigla implica um reconhecimento por parte dos pesquisadores de que o nosso planeta está em situação de emergência ambiental. A poluição alcançou os rios, os solos, o ar, os mares e oceanos. Os recursos naturais estão sendo esgotados e a perda de biodiversidade biológica é crescente. A urbanização desordenada e acelerada, as indústrias e os meios de transporte precisam ser repensados, bem como o consumo exagerado de todos os recursos.

Vilches, Pérez e Praia (2011) argumentam que não basta esperar e acreditar que as respostas a tantos problemas ambientais estejam apenas nas mãos de especialistas em tecnociência, que geralmente trazem as soluções de maneira fácil e rápida. Para os autores, há mudanças que dependem de ações cidadãs responsáveis como, por exemplo, com relação aos agrotóxicos e o uso de produtos que não prejudicam o ambiente.

$\mathrm{Na}$ abordagem da problemática ambiental, o conhecimento científico é imprescindível, mas não é suficiente para diminuir a destruição da natureza e dos diversos animais que têm o direito de viver em seu hábitat. A valorização à cultura de cada região, com sua religião, comida e vestuário contribui para enaltecer o próprio ser humano, que não precisa consumir exageradamente os produtos que o capitalismo impõe através da mídia, como sendo um caminho para ser feliz e aceito. Portanto, é necessário que esse sistema que visa apenas o crescimento econômico seja analisado criticamente.

A educação CTS defende um novo tipo de alfabetização fundamentada no contexto da ética, responsabilidade individual e coletiva. Ela representa uma forma diferente de ver o mundo. A visão mecanicista, compartimentada da vida é substituída por um paradigma que reconhece as complexidades holística e integrada de toda a vida. O conceito de sustentabilidade encapsula e respeita o valor intrínseco de toda a vida na Terra. [...] Por conseguinte, o ambiente torna-se uma das características orientadoras da educação CTS (PEDRETTI, 1997, p. 1215, tradução nossa).

O movimento CTS ou enfoque CTS (AULER; BAZZO, 2001) quando pensado para ser trabalhado em sala de aula, apresenta denominações como: currículo CTS, pedagogia CTS, abordagem CTS, educação CTS (AIKENHEAD, 2009; PEDRETTI, 1997; SOLOMON; AIKENHEAD, 1994; ZIMAN, 1994a). 
Na educação CTS ${ }^{5}$ é importante que os estudantes saibam e compreendam que a ciência e a tecnologia se desenvolvem em um contexto social, político, econômico, ético e religioso. Por exemplo, muitas investigações científicas estão associadas a grandes empresas. As pesquisas são, na maioria, motivadas pela possibilidade de trazerem grandes lucros. O jargão científico pode estar obscurecido por motivações políticas, e isso precisa ser discutido em sala de aula (AIKENHEAD, 2009).

A mesma ciência que produz antibióticos e outros medicamentos que ajudam a salvar vidas, também está a serviço da produção de armas muito potentes, como as biológicas, as com mísseis de longo alcance e as bombas atômicas, entre outras. Para a ciência se eximir da responsabilidade da criação e venda dos produtos mencionados anteriormente, foi criado ideologicamente um modelo linear de inovação tecnológica, como se a tecnologia viesse depois do conhecimento científico, havendo uma distinção entre ciência e tecnologia (ZIMAN, 1994b).

É como se os cientistas produzissem suas descobertas de forma pura, neutra e despretensiosa. Esse conhecimento é transferido para as empresas de engenharia e indústrias farmacêuticas que, após um longo processo de desenvolvimento e adequação, novos produtos chegam às lojas, farmácias, hospitais e ao campo de batalha. Assim, os cientistas ficam isentos de qualquer responsabilidade.

Sismondo (2008) sistematizou estudos associados ao financiamento da indústria farmacêutica na pesquisa de novos medicamentos. O autor menciona que $70 \%$ do financiamento de pesquisas com testes clínicos é realizado pelas indústrias farmacêuticas, cujos resultados estão fortemente influenciados por seus interesses nos lucros gerados pela venda dos futuros medicamentos. Nesse sentido, há estreita ligação entre os resultados das pesquisas com o financiamento que elas recebem, inclusive com relação às metodologias de análise realizadas nos testes.

Por exemplo, há pesquisas que indicam que medicamentos patrocinados por empresas farmacêuticas, indicados para combater depressão, reumatismo, alergias, problemas cardiovasculares, além de analgésicos e vacinas, tendem a apresentar resultados altamente satisfatórios, quando comparados com os medicamentos financiados por organizações sem fins lucrativos (SISMONDO, 2008).

Se o propósito está na venda dos medicamentos, pode-se entender que não há interesse na cura de qualquer enfermidade, mas em produzir medicamentos paliativos que, não raramente, geram efeitos colaterais, tratáveis com mais remédios. Essa situação favorece a manutenção do consumo, por meio de uma ideologia salvacionista. Por isso, é importante que esta informação chegue à população, para que as pessoas possam ter um olhar mais crítico para a indústria farmacêutica, que atualmente afeta a qualidade de vida de todos. Os estudantes precisam ser preparados para terem controle sobre suas próprias vidas, ao lidarem com as inovações científicas e tecnológicas na sociedade.

Para Ziman (1994b), esse modelo de conceber o desenvolvimento científico está equivocado. Isto não significa colocar a responsabilidade inteiramente nas mãos dos cientistas, mas perceber que eles são seres humanos que vivem e trabalham em uma sociedade capitalista. Ao mesmo tempo, é importante reconhecer que diversos cientistas não aceitam realizar determinadas pesquisas como, por exemplo, com as células-tronco

\footnotetext{
${ }^{5}$ Neste trabalho optamos pela denominação educação CTS.
} 
embrionárias (SOUZA, 2011). Portanto, pode-se verificar que o movimento CTS envolve um amplo campo de conhecimentos.

Desse modo, em seu livro "Ensino e Aprendizagem sobre Ciência e Sociedade", Ziman (1985) foi o primeiro a sistematizar estratégias de educação CTS. No entanto, esse mesmo autor também constatou que os princípios do movimento CTS na educação acabaram sendo dissolvidos por abordagens consideravelmente diferentes (SADLER, 2004; ZIMAN, 1985). Por exemplo, algumas abordagens apenas relacionavam os avanços científicos e tecnológicos às suas aplicações sociais, outras davam ênfase aos aspectos históricos da ciência, a fim de que os alunos compreendessem como a ciência evolui.

Dentre as abordagens analisadas por Ziman (1985), a que mais contribui para uma renovação no ensino de ciências é a que o autor denominou de problemática, pois aborda questões controversas que envolvem a ciência e a sociedade. Seguindo este raciocínio, Erminia Pedretti (1997), em seu artigo "Crise na fossa séptica: um estudo de caso de ciência, tecnologia e sociedade no ensino de uma escola primária", abordou a importância de se trabalhar questões CTS a fim de promover o desenvolvimento de cidadãos alfabetizados tecnologicamente, capazes de tomar decisões responsáveis e de agir sobre essas decisões.

Questões controversas e polêmicas que envolvem a ciência, a tecnologia e a sociedade são denominadas de questões CTS (PEDRETTI, 1997; WIESENMAYER; RUBBA, 1999). Pedretti et al. (2008) realizaram uma pesquisa utilizando a expressão questões CTSA. Neste trabalho usaremos o termo questões sociocientíficas (RATCLIFFE; GRACE, 2003; SADLER, 2004).

\section{A natureza das questões sociocientíficas}

As questões sociocientíficas são abertas, de caráter sociocientífico, e que consideram, predominantemente, conteúdos mais de fronteira, sobre os quais se podem encontrar diferentes posicionamentos, tanto de cientistas como da sociedade em geral. Isto pode ocorrer também pelo fato de as informações poderem se apresentar de maneira incompleta ou conflituosa (RATCLIFFE; GRACE, 2003).

Os autores argumentam que as questões sociocientíficas devem ter uma base na ciência e um potencial impacto na sociedade. Podem estar relacionadas a questões ambientais, assim como podem ser passageiras. Por exemplo, o diclorodifeniltricloroetano (DDT) é um agrotóxico cujo uso já foi polêmico (CARSON, 2010). Atualmente seu uso é proibido, inclusive no Brasil, pois já foi confirmada a sua periculosidade aos animais e ao ambiente.

Ratclife e Grace (2003) também explicam que existem questões sociocientíficas de abrangência nacional, como a instalação de mais uma usina nuclear, ou ter impacto apenas em determinados grupos ou indivíduos. Por isso, elas também envolvem a formação de opinião em nível individual e coletivo; e isto está associado a valores pessoais e éticos, além de poder envolver uma análise de probabilidade e custo-benefício em que o risco interage com esses valores.

Sadler (2004) considera que as questões sociocientíficas são dilemas sociais ligados à tecnologia científica. Para o autor, o processo de encaminhamento dessas questões é melhor caracterizado pelo raciocínio informal, ou seja, uma maneira de pensar não institucionalizada, que identifica e avalia posicionamentos em resposta a situações complexas. O raciocínio informal compreende o desenvolvimento de valores éticos, morais, culturais e sociais, podendo ter ou não influência da religião. 
O autor também explica que as questões sociocientíficas não sugerem que a ciência e a sociedade sejam entidades independentes, pelo contrário, "[...] todos os aspectos da ciência são inseparáveis da sociedade da qual eles surgem." (SADLER, 2004, p. 513, tradução nossa).

Como exemplos de temas controversos e polêmicos é possível mencionar as formas de obtenção de energia elétrica, as terapias com células-tronco embrionárias, os alimentos transgênicos, a nutrição vegetariana/vegana, a clonagem, entre outros, que podem ser trabalhados em sala de aula para promover discussões, reflexão e conhecimento aos estudantes, mas, principalmente, auxiliar a desenvolver a responsabilidade cidadã na tomada de decisões onde esses assuntos estão envolvidos.

É importante não confundir a resolução de um problema complexo com uma questão sociocientífica, pois esta não tem uma única solução. Cada pessoa ou cada grupo de pessoas envolvidas em uma questão sociocientífica vai encontrar uma maneira de encarar, de lidar e até de resolver ou não um determinado assunto científico e controverso.

Ratclife e Grace (2003) nos apresentam três exemplos de perguntas cuja solução pode ser considerada polêmica. A primeira pergunta é: —Você prefere alimentos livres de pragas ou evitar danos em longo prazo à camada de ozônio?; a segunda: —Você acha que a vacinação deve ser obrigatória ou ficar a critério das pessoas? e a terceira: —Acha justo gastar dinheiro público na pesquisa espacial em busca de vida extraterrestre ou o dinheiro deve ser gasto para buscar novas fontes de energia? Os autores esclarecem que essas perguntas são exemplos muito simples, mas que na vida atual as questões sociocientíficas podem ser muito mais difíceis e complexas.

Outro exemplo a ser relatado é sobre o direito à vida de embriões humanos que não foram utilizados na fertilização in vitro. Tais embriões podem ser utilizados em pesquisas com células-tronco. A Lei de Biossegurança nº 11.105 de 2005, em seu artigo 5, inciso II, prevê que os embriões não utilizados e congelados por três anos ou mais podem ser aproveitados nas pesquisas envolvendo células-tronco, desde que haja o consentimento dos genitores. Na Resolução n 2.013 de 2013, o Conselho Federal de Medicina ampliou o prazo do descarte para cinco anos, e não apenas para pesquisas com células-tronco. Casais que não conseguem ter filhos por meio de seus próprios gametas também podem receber embriões com a autorização dos doadores. Ainda assim, a controvérsia não está resolvida, pois muitas pessoas não concordam com isso. Líderes religiosos têm opiniões divergentes, assim como cientistas e demais pessoas da sociedade. Guimarães (2011) discute e traz elementos importantes que tratam desse assunto controverso.

Portanto, uma questão sociocientífica não deve ser trabalhada em sala de aula para resolver um problema científico. Ela vem para promover uma metodologia de ensino em que o professor contemple as diferentes opiniões dos alunos (SADLER, 2004; SANTOS; MORTIMER, 2009), para promover a compreensão das imbricadas relações entre a ciência e a tecnologia, imersas e dominantes na sociedade, a fim de proporcionar uma reflexão crítica e um posicionamento autônomo e responsável sobre tal dinâmica (REIS, 2004; REIS; GALVÃO, 2005). Além disso, possibilita o enriquecimento da "[...] criatividade e a imaginação dos estudantes sobre as possíveis alternativas, fornecendo poder e liberdade para examinar e questionar questões sociais relacionadas com a ciência e a tecnologia." (PEDRETTI, 1997, p. 1227, tradução nossa).

Enfim, as discussões devem proteger as diversas opiniões entre os participantes e não forçar um consenso, a menos que o grupo tenha planejado uma perspectiva e um plano comum (RUDDUCK, 1986). 


\section{Interdisciplinaridade no trabalho com questões sociocientíficas}

O conceito de interdisciplinaridade é relativamente recente. Foi a partir da década de 1970 que ocorreu o início dos estudos sobre o assunto. Atualmente, a interdisciplinaridade pode estar sendo reduzida a um mero arranjo entre as disciplinas ou à uma simples colaboração dos professores, por ter se tornado um modismo educacional. Dessa forma, alguns projetos interdisciplinares apresentam práticas disciplinares, com justaposição de atividades. Conforme Paviani (2008) é preciso identificar o que ele chama de falsa e verdadeira interdisciplinaridade, para evitar que o termo seja utilizado de forma superficial, prejudicando seu desgaste conceitual crescente.

Trabalhar de maneira interdisciplinar na escola pode implicar em uma integração e flexibilização das disciplinas, sem eliminá-las, mas valorizar os conteúdos construídos historicamente de cada área do conhecimento. Há também tipos e níveis diferentes de interdisciplinaridade, pois ela não é um fenômeno linear, uniforme e homogêneo. Desse modo, não há um único modelo de ação interdisciplinar predeterminado (PAVIANI, 2008).

No Brasil, a interdisciplinaridade é conceituada como um novo posicionamento diante do conhecimento e da possibilidade de abertura a novos questionamentos de aspectos tanto ocultos, como expressos no ato de aprender. Na educação, ela favorece novos olhares para as dimensões socioculturais humanas e novas maneiras de aproximação da realidade social (FAZENDA, 2011).

No trabalho interdisciplinar, o assunto em questão é estudado sem perder a visão do todo. Ele é tratado sob diferentes perspectivas, de maneira complexa (PAVIANI, 2008). Essa é uma das características das questões sociocientíficas, que são necessariamente interdisciplinares, já que uma única disciplina não é capaz de dar encaminhamento à questão formulada. Por ser aberta, não se pode pretender uma solução geral. A possível solução é situada, contextualizada e pode ser que sirva para outros contextos, pode ser que não.

O trabalho com as questões sociocientíficas demanda que o docente trabalhe de maneira interdisciplinar, pela própria situação complexa em que tais questões emergem. Podem estar presentes nas discussões conceitos científicos de biologia, geologia, física, química, história, sociologia, filosofia, matemática, economia, política, entre outras, e valores éticos, morais e religiosos (PEDRETTI, 1997; SANTOS; MORTIMER, 2009). Cada questão sociocientífica vai determinar quais conceitos são necessários para discuti-la; e o nível de escolaridade dos estudantes também vai limitar a profundidade da abordagem de tais conceitos.

Porém, ainda há diversas dificuldades para exercer a interdisciplinaridade. Uma delas é que há muitas pesquisas realizadas no Brasil, mas que são pouco conhecidas pela maioria dos educadores (FAZENDA, 2011). Para tentar superar esses desafios, a autora apresenta cinco princípios que "[...] subsidiam uma prática docente interdisciplinar: humildade, coerência, espera, respeito e desapego." (FAZENDA, 2011, p. 21).

Portanto, não é uma tarefa fácil para o professor, pois é preciso disposição para procurar os conhecimentos que ele ainda não conhece. No entanto, se não houver espaço para o comodismo e a insegurança, a interdisciplinaridade pode trazer inúmeros benefícios educacionais, em especial à compreensão dos estudantes e à sua participação no trabalho com as questões sociocientíficas. 


\title{
Questões sociocientíficas: podem estar presentes na mídia, ou não
}

Geralmente, a mídia tem divulgado informações sobre novas descobertas científicas. Algumas abordam assuntos controversos e polêmicos, como por exemplo, reportagens sobre organismos geneticamente modificados (transgênicos), células-tronco, clonagem, formas de obtenção de energia elétrica, vida inteligente fora da Terra, uso de agrotóxicos, alimentação vegetariana ou vegana, entre outros (MARTíNEZ-PÉREZ; CARVALHO, 2012; RATCLIFFE; GRACE, 2003; SADLER, 2004).

\begin{abstract}
Muitas áreas de debate na mídia e na política social se relacionam com questões sociocientíficas. Enquanto escrevemos esse texto, há manchetes de notícias no rádio - elas incluem a campanha do governo irlandês contra uma nova usina de reprocessamento nuclear por causa da poluição radioativa; preocupações sobre a maneira pela qual o surto de febre aftosa britânica tinha sido tratado; provas de DNA em um julgamento por assassinato. Essas são típicas questões sociocientíficas [...] (RATCLIFFE; GRACE, 2003, p. 1, tradução nossa).
\end{abstract}

Há temas sociocientíficos que já estiveram presentes na mídia e que não estão mais, porém, ainda afetam muitas pessoas. Por exemplo, o primeiro bebê de proveta nasceu em 1978, gerado a partir da fertilização in vitro, onde a fecundação é realizada no laboratório. Este tema já esteve presente na mídia do mundo todo, quando o procedimento foi realizado pela primeira vez, e atualmente tem sido divulgado para demonstrar o número crescente de casais que recorrem à essa técnica. No entanto, por questões religiosas e afetivas muitos casais não aceitam este método para terem seus filhos, outros não têm condições monetárias para pagarem o caro procedimento, que é oferecido pelo Sistema Único de Saúde (SUS) desde dezembro de 2012, mas em apenas alguns centros de saúde no país.

Há muitos outros exemplos, desde as construções de usinas hidrelétricas, como a de Belo Monte, no Pará, até o excesso de medicamentos prescritos, muitas vezes, sem necessidade a crianças, jovens e adultos, a serviço da indústria farmacêutica. Um exemplo atual é o Transtorno do Déficit de Atenção com Hiperatividade (TDAH), caso em que até mesmo o diagnóstico pode ser polêmico e controverso.

Dessa forma, as questões sociocientíficas "[...] são frequentemente relatadas pela mídia, e sua apresentação deve estar baseada nos propósitos do comunicador [...]" (RATCLIFFE; GRACE, 2003, p. 2, tradução nossa), ou seja, os meios de comunicação produzem e divulgam informações baseadas, geralmente, no interesse dos grupos dominantes (ADORNO, 1994). Portanto, podem ser um tema controverso que já foi divulgado na mídia, que está sendo divulgado no momento, ou que ainda não está presente e talvez, nunca estará por não contemplar os interesses daqueles que detêm seu controle. Desse modo, a formação para uma visão crítica com relação à mídia é fundamental.

\section{Considerações}

Defendemos neste texto que a perspectiva de educação por meio das questões sociocientíficas no ensino de ciências se faz relevante porque auxilia os estudantes a construírem seus próprios argumentos e decisões, para escolherem qual desenvolvimento 
científico e tecnológico é necessário e adequado à vida de cada um. Por exemplo, existem tratamentos estéticos extremamente dolorosos e invasivos. Cabe a cada indivíduo analisar criticamente até que ponto vale a pena se submeter a um procedimento que pode custar, além de dinheiro, seu próprio bem-estar.

Por causa dos diversos meios de comunicação e divulgação, cada vez mais pessoas se interessam pelas aplicações da ciência e tecnologia, em especial em novas descobertas médicas da área da saúde, mas também em questões ambientais, assim como em novas invenções. Neste sentido é provável que as questões sociocientíficas continuem a ser do interesse das futuras gerações, já que os desafios ambientais de uma população que não para de crescer, juntamente com os avanços na genética molecular e na ciência médica colocarão em destaque esse tipo de questão (RATCLIFE; GRACE, 2003; SADLER (2004).

Assim, mais que antes é preciso investir na formação de professores para o ensino de ciências, de modo que compreendam a ciência como um empreendimento constantemente em evolução, dinâmico e controverso, com múltiplas interações científicas e tecnológicas com implicações na sociedade (REIS; GALVÃO, 2008).

Além disso, é preciso que os professores sejam formados para a autonomia crítica, isto é, que tenham uma verdadeira formação, já que as questões sociocientíficas não estão prontas, elas são construídas em sala de aula. O que a mídia apresenta são os temas ou assuntos controversos, mas estes precisam ser elaborados junto com os estudantes para os propósitos formativos que o professor almeja. Apenas os professores autônomos, conscientes da importância de seu papel político e social e com capacidade de tomar decisões poderão ensinar ciências de maneira mais real, a fim de que a educação científica possa auxiliar na formação de cidadãos críticos e atuantes, responsáveis em suas decisões.

Saber se posicionar e conseguir ver os avanços científicos como oriundos de um processo histórico, social, político e econômico, é ter uma visão crítica sobre o desenvolvimento científico e tecnológico. Essa visão crítica com relação ao empreendimento tecnocientífico pode ser estimulada e vivenciada desde os anos iniciais do Ensino Fundamental, com o exercício da argumentação, proporcionado por metodologias de ensino que valorizem as opiniões dos estudantes, baseadas nos conhecimentos estudados em sala de aula e no ser humano que está em processo de formação. 


\section{Referências}

ADORNO, W. T. A indústria cultural. In: COHN, Gabriel. Theodor Adorno. Sociologia. São Paulo: Ática, 1994.

AIKENHEAD, G. S. Educação Científica para todos. 1. ed. Tradução Maria Teresa Oliveira. Mangualde, Portugal: Edições Pedago, 2009.

AULER, D.; BAZZO, W. A. Reflexões para a implementação do movimento CTS no contexto educacional brasileiro. Ciência \& Educação, Bauru, v.7, n.1, p.1-13, 2001.

BAZZO, W. A. Ciência, Tecnologia e Sociedade: e o contexto da educação tecnológica. 4. ed. Florianópolis: Ed. da UFSC, 2014.

BORTOLETTO, A.; CARVALHO, L. P. de. Uma proposta de formação continuada de professores de ciências e matemática na interface do agir comunicativo e das questões sociocientíficas. AMAZÔNIA - Revista de Educação em Ciências e Matemática, Belém, v. 9, no 17, p.141-160, jul./dez. 2012.

BRASIL. Lei no 11.105, de 24 de março de 2005. Regulamenta e estabelece normas de segurança e mecanismos de fiscalização de atividades que envolvam organismos geneticamente modificados - OGM e seus derivados, cria o Conselho Nacional de Biossegurança - CNBS. Diário Oficial da União, Brasília, 28 mar. 2005. Disponível em: http://www.planalto.gov.br/ccivil_03/_ato2004-2006/2005/lei/111105.htm. Acesso em: 16 fev. 2015.

CARSON, R. Primavera Silenciosa. 1. ed. Tradução Claudia Sant'Anna Martins. São Paulo: Gaia, 2010.

CRUZ, G. B. da. Curso de Pedagogia no Brasil: História e formação com pedagogos primordiais. Rio de janeiro: Wak, 2011.

FAZENDA, I. C. A. Integração e interdisciplinaridade no ensino brasileiro: efetividade ou ideologia. 6. ed. São Paulo: Loyola Jesuítas, 2011.

GALVÃO, C.; REIS, P.; FREIRE, S. A discussão de controvérsias sociocientíficas na formação de professores. Ciência \& Educação, Bauru, v. 17, n. 3, p. 505-522, 2011.

GUIMARÃES, M. A. Raciocínio informal e a discussão de questões sociocientíficas: o exemplo das células-tronco humanas. 2011. 218 f. Tese (Doutorado em Educação para a Ciência). Faculdade de Ciências, Universidade Estadual Paulista, Bauru, 2011.

KUHN, T. A estrutura das revoluções científicas. 6.ed. São Paulo: Perspectivas, 2001.

MARCONDES, M. E. R. et al. Materiais instrucionais numa perspectiva CTSA: uma análise de unidades didáticas produzidas por professores de química em formação continuada.

Investigações em ensino de ciências, v.14, n. 2, p. 281-298, 2009.

MARTíNEZ, L. F. P. Ensino de ciências com enfoque ciência, tecnologia, sociedade e ambiente (CTSA) a partir de questões sociocientíficas (QSC). In: Questões sociocientíficas na prática docente: Ideologia, autonomia e formação de professores [online]. São Paulo: Editora UNESP, 2012. Disponível em: http://books.scielo.org/id/bd67t/pdf/martinez9788539303540-04.pdf. Acesso em: 10 abr. 2017. 
MARTíNEZ-PÉREZ, L.; CARVALHO, W. L. P de. Contribuições e dificuldades da abordagem de questões sociocientíficas na prática de professores de ciências. Educação e Pesquisa, São Paulo, v. 38, n. 3, p. 727-741, 2012.

PAVIANI, J. Interdisciplinaridade: conceitos e distinções. 2.ed. rev. Caxias do Sul, RS: Educs, 2008.

PEDRETTI, E. Septic tank crisis: A case study of science, technology and society education in an elementary school. International Journal of Science Education, Ontario, v. 19, n.10, p. 12111230. 1997.

RATCLIFFE M.; GRACE M. Science education for citizenship: teaching socioscientific issues. Maidenhead: Open University Press, 2003.

REIS, P. Controvérsias sócio-científicas: discutir ou não discutir? Percursos de aprendizagem na disciplina de ciências da Terra e da vida. 2004. Tese (Doutorado) Faculdade de Ciências da Universidade de Lisboa, Lisboa. Disponível em: http://pwp.netcabo.pt/PedroRochaReis. Acesso em: 25 jan. 2015.

REIS, P.; GALVÃO, C. Controvérsias sócio-científicas e prática pedagógica de jovens professores. Investigações em ensino de ciências, Porto Alegre, v.10, n. 2, p. 131-160, 2005.

REIS, P.; GALVÃO, C. Os professores de Ciências naturais e a discussão de controvérsias sociocientifícas: dois casos distintos. Revista electrónica de Enseñanza de la Ciencias, Vigo, v. 7, n. 3, p. 746-772, 2008.

RUDDUCK, J. A strategy for controversial issues in the secondary school. In: WELLINGTON, J. J. (Edited). Controversial issues in the curriculum. Basil Blackwell Ltd. England. 1986.

SADLER, T. D. Informal reasoning regarding socioscientific issues: A critical review of research. Journal of Research in Science Teaching, v. 41, n. 5, p. 513-536, 2004.

SANTOS, W. L. P.; MORTIMER, E. F. Abordagem de aspectos sociocientíficos em aulas de ciências: possibilidades e limitações. Investigações em ensino de ciências, v. 14, n. 2, p. 191 218, 2009 .

SASSERON, L. H.; CARVALHO, A. M. P. almejando a alfabetização científica no ensino fundamental: a proposição e a procura de indicadores do processo. Investigações em ensino de ciências, v. 13, n. 3, p.333-352, 2008.

SISMONDO, S. Pharmaceutical company funding and its consequences: A qualitative systematic review. Contemporary Clinical Trials, v. 29, p.109-113, 2008. Disponível em: https://papers.ssrn.com/sol3/papers.cfm?abstract_id=1143764. Acesso em: 10 abr. 2017. SOLOMON, J. Teaching science, technology and society. Buckingham: Open University Press, 1993.

SOLOMON, J.; AIKENHEAD, G. (Editors). STS Education: international perspectives on reform. New York: Teachers College, 1994.

SOUZA, I. M. A. Células tronco: considerações sobre o regime de verdade e o regime de esperança. In: PORTO, C. M., BROTAS, A. M. P., BORTOLIERO, S. T., (Orgs). Diálogos entre ciência e divulgação científica: leituras contemporâneas [online]. Salvador: EDUFBA, 2011, p. 153-178. Disponível em: http://books.scielo.org/id/y7fvr/pdf/porto-9788523211813-08.pdf. Acesso em: 04 abr. 2017. 
VILCHES, A.; PÉREZ, D. G.; PRAIA, J. De CTS a CTSA: educação por um futuro sustentável. In: SANTOS, W. L. P.; AULER, D. (Orgs.). CTS e educação científica: desafios, tendências e resultados de pesquisas. Brasília: Editora Universidade de Brasília, 2011.

WIESENMAYER, R. L.; RUBBA, P. A. The Effects of STS Issue Investigation and Action Instruction Versus Traditional Life Science Instruction on Seventh Grade Students' Citizenship Behaviors. Journal of Science Education and Technology, Luxembourg, v. 8, n. 2, p. 137-144, 1999.

ZIMAN, J. Enseñanza y aprendizaje sobre la ciencia y la sociedad. Traducción José Andrés Pérez Carballo. México, D. F.: Fondo de Cultura Económica, 1985.

ZIMAN, J. The Rationale of STS Education is in the Approach. In: SOLOMON, J.; AIKENHEAD, G. (Editors). STS Education: international perspectives on reform. New York: Teachers College, 1994a.

ZIMAN, J. Public understanding of science: constituencies and stereotypes. In: GAGO, J. M. O futuro da cultura científica. Lisboa: Instituto de Prospectiva, 1994b. 